\title{
Aortic pulse wave velocity in normals and heart failure patients
}

\author{
Yi Wang ${ }^{1,2^{*}}$, Jie J Cao ${ }^{1,2}$, Yang Cheng ${ }^{1}$, Nathaniel Reichek ${ }^{1,2}$ \\ From 15th Annual SCMR Scientific Sessions \\ Orlando, FL, USA. 2-5 February 2012
}

\section{Summary}

Aortic pulse wave velocity is altered by normal aging, as well as vessel wall pathology. We evaluated aortic compliance and its relationship to age in normals and patients with heart failure.

\section{Background}

Aortic compliance (AC) can be evaluated noninvasively and its reduction with aortic pathology and age in normals has been demonstrated with both MRI and Doppler echo methods. Aortic pulse wave velocity (PWV), a measurement of the flow pulse traveling along aorta as a surrogate for $\mathrm{AC}$, can be assessed using a single breath-hold phase contrast (PC) imaging technique. Congestive heart failure is often associated with a chronic cardiac remodeling process in which the myocardium either cannot eject blood very well (systolic heart failure); or the myocardium is stiff and ventricular chambers do not fill with blood easily (diastolic heart failure). We hypothesize that aortic stiffness is increased in the CHF population and its age dependency differs from that in normals.

\section{Methods}

As normal controls, 196 healthy volunteers gave informed consent (96 male, age: $61.3 \pm 14.2$ ) and were screened to exclude hypertension, hyperlipidemia and cardiovascular disease. Twenty two CHF patients had been referred for clinical CMR study with LVEF $<55 \%$. Using the 'candy cane' view of aorta, an axial plane through the ascending and descending aorta at the pulmonary artery level was prescribed and a through-plane velocity encoded $\mathrm{PC}$ cine imaging was acquired with $\mathrm{VENC}$ of $150 \mathrm{~cm} / \mathrm{s}$, TR $/ \mathrm{TE} / \mathrm{FA}=98 \mathrm{~ms} / 2.9 \mathrm{~ms} / 15^{\circ}$ and voxel spatial resolution $1.3 \times 2 \times 6 \mathrm{~mm} 3$ on a $1.5 \mathrm{~T}$ MRI scanner. The distance traveled by the aortic pulse wave, $\Delta \mathrm{D}$, was determined as the distance along the center line between the axial sections as imaged in the "candy cane' image. For flow pulse onset, the cross correlation between the first halves of the ascending and descending aortic flow curves was calculated by varying the relative time shift between them. The $\Delta \mathrm{t}$ was the time shift at the maximal correlation. We then calculated $\mathrm{PWV}=\Delta \mathrm{D} /$ $\Delta \mathrm{t}$. Linear regression was used to determine the relationships between PWV and age at both groups.

\section{Results}

PWV in CHF and in normals correlate with age, as shown in the Figure as left graph and right graph of scatter plots, respectively. The linear regression in normals is: $\mathrm{PWV}(\mathrm{m} / \mathrm{s})=-5.548+0.2601 *$ Age; while in CHF patients: PWV $(\mathrm{m} / \mathrm{s})=-1.277+0.1879 * a g e$; However, the relationship is stronger in normals. Young and elderly patients with CHF had lower PWV than normals, likely due to reduced stroke volume and blood pressure in the CHF group.

\section{Conclusions}

Aortic stiffness increases with age in CHF patients, but the slope seems to differ from CHF patients to normals.

\section{Funding}

None.

Author details

${ }^{1}$ St. Francis Hospital, Roslyn, NY, USA. ${ }^{2}$ SUNY, Stony Brook, NY, USA.

Published: 1 February 2012

${ }^{1}$ St. Francis Hospital, Roslyn, NY, USA

Full list of author information is available at the end of the article

(c) 2012 Wang et al; licensee BioMed Central Ltd. This is an open access article distributed under the terms of the Creative Commons Attribution License (http://creativecommons.org/licenses/by/2.0), which permits unrestricted use, distribution, and reproduction in any medium, provided the original work is properly cited. 


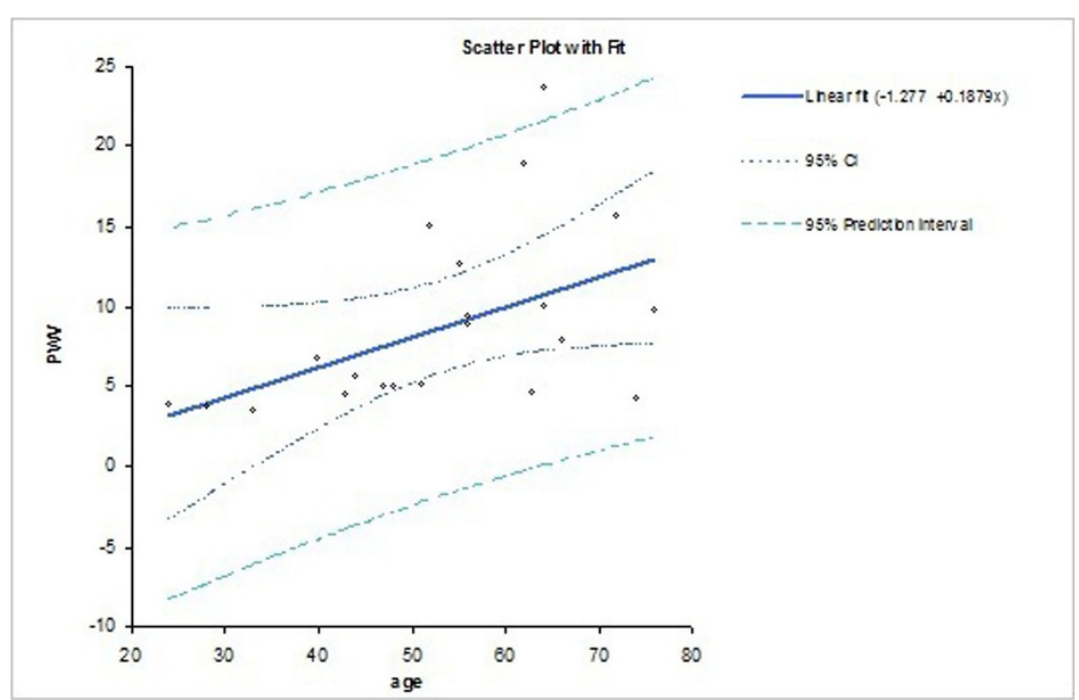

Figure 1 The scatter plot of the fitting curve between pulse wave velocity and age: CHF patients with $R 2=0.24, p=0.02, n=22$.

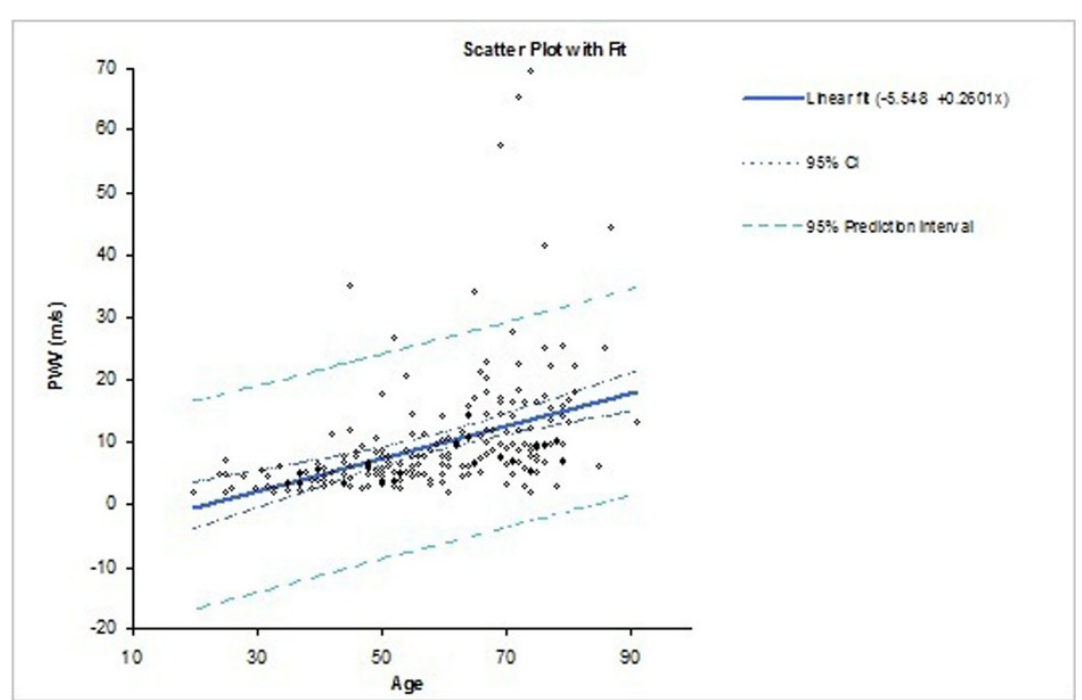

Figure 2 The scatter plot of the fitting curve between pulse wave velocity and age: normals with $R 2=0.18, p<0.01, n=196$.

doi:10.1186/1532-429X-14-S1-P127

Cite this article as: Wang et al:: Aortic pulse wave velocity in normals and heart failure patients. Journal of Cardiovascular Magnetic Resonance 2012 14(Suppl 1):P127.
Submit your next manuscript to BioMed Central and take full advantage of:

- Convenient online submission

- Thorough peer review

- No space constraints or color figure charges

- Immediate publication on acceptance

- Inclusion in PubMed, CAS, Scopus and Google Scholar

- Research which is freely available for redistribution

Submit your manuscript at www.biomedcentral.com/submit 